\title{
O Programa Bolsa Família entre os povos indígenas: o impacto entre os Akwẽ-Xerente
}

\author{
The Bolsa Familia Program among indigenous peoples: the impact among Akwẽ- \\ Xerente
}

\author{
Cássia Araújo Moraes Braga* \\ Reijane Pinheiro da Silva**
}

\section{RESUMO}

Os projetos de desenvolvimento já implantados na região do atual Tocantins trouxeram vários impactos sociais, ambientais e culturais ao povo Xerente, que passou a demandar intervenção governamental para ter acesso aos direitos sociais básicos. Vários povos indígenas de todo o Brasil vivenciam escassez de recursos naturais que antes garantiam sua sobrevivência e sustento. Muitos deles foram inseridos no Programa Bolsa Família (PBF). Esta pesquisa buscou analisar o impacto do PBF na realidade dos Akwẽ-Xerente, considerando os aspectos da diversidade étnica em questão. A metodologia adotada fundamentou-se em uma abordagem qualitativa, a partir da pesquisa de campo. A análise de resultados identificou que o programa garante o acesso a alimentos, saúde, educação e diminuiu o trabalho infantil.

PALAVRAS-CHAVE: Programa Bolsa Família. Povos indígenas. Akwẽ-Xerente. Assistência Social. Segurança alimentar.

\begin{abstract}
The development projects already implemented in the region of the current Tocantins brought several social, environmental and cultural impacts to the Xerente people, who started to demand government intervention to gain access to basic social rights. Several indigenous peoples across Brazil experience a shortage of natural resources that previously guaranteed their survival and livelihood. Many of them were included in the Bolsa Familia Program (PBF). This research sought to analyze the impact of the PBF on the reality of the Akwe-Xerente, considering the aspects of ethnic diversity in question. The methodology adopted was based on a qualitative approach, based on field research. The analysis of results identified that the program guarantees access to food, health, education and reduced child labor.
\end{abstract}

KEYWORDS: Bolsa Família Program. Indigenous Peoples. Akwẽ-Xerente. Social assistance. Food safety.

\footnotetext{
* Graduada em Serviço Social e mestre em Desenvolvimento Regional pela Universidade Federal do Tocantins. Assistente Social no Instituto Federal de Educação, Ciência e Tecnologia do Tocantins.

** Doutora em Antropologia Social pela Universidade Federal do Rio Grande do Sul. Mestre em Sociologia pela Universidade Federal de Goiás. Graduada em Ciências Sociais pela Universidade Federal de Goiás. Professora adjunta III da Fundação Universidade Federal do Tocantins.
} 


\section{Introdução}

O Programa Bolsa Família (PBF) foi criado por meio da Medida Provisória n. 132, de 20 de outubro de 2003, convertida na Lei n. 10.386/2004, com o objetivo de beneficiar famílias pobres e extremamente pobres inscritas no Cadastro Único ${ }^{1}$ (Cadúnico). É um programa de transferência de renda, que oportuniza o acesso aos direitos sociais, principalmente ao direito à saúde, assistência social e educação, além de gerar autonomia e capacitar para inserção no mercado de trabalho. A seleção dos (as) beneficiários (as) fica sob a responsabilidade dos órgãos municipais de assistência social, sendo que a gerência do programa é do Ministério de Desenvolvimento Social e Combate à Fome (MDS) e a operacionalização do pagamento fica sob a responsabilidade da Caixa Econômica Federal (CEF).

Conforme o Censo 2010, 896.917 pessoas se autodeclararam indígena no Brasil, sendo que 324.834 pessoas foram registradas vivendo nas cidades e 572.083 em áreas rurais (IBGE, 2010). Conforme o site do MDS, em junho de 2018, 13.736 .341 famílias indígenas recebiam o Bolsa Família.

Segundo informações do MDS (2018), o Tocantins tem 121.374 famílias beneficiadas pelo PBF, correspondendo a $23,58 \%$ da população do estado. Conforme o Censo de 2010 do IBGE, Tocantínia - TO tem 6.736 habitantes, sendo considerado pela política de Assistência Social como município de Pequeno Porte ${ }^{2}$. O município tem 1.569 famílias cadastradas no Cadastro Único, sendo 718 famílias indígenas. Foram beneficiadas 891 famílias neste município, sendo 519 famílias indígenas.

O PBF foi pensado para atender às famílias em vulnerabilidade social, entretanto, as orientações, forma de cadastramento e inclusão não foram pensadas visando atender às especificidades das famílias brasileiras (QUERMES; CARVALHO, 2013; BORGES, 2016; BRASIL, 2017). Neste artigo apresentaremos o impacto que o programa trouxe ao modo de vida dos

1 O Cadastro Único para Programas Sociais ou Cadúnico é um instrumento de coleta de dados e informações que objetiva identificar todas as famílias de baixa renda existentes no país, para fins de inclusão em programas de assistência social e redistribuição de renda.

2 O Sistema Único de Assistência Social se utiliza da divisão de municípios por população para propor ações de proteção básica e/ou especial de média e alta complexidade. Municípios de Pequeno Porte são os com população de até 20.000 habitantes. 
(as) indígenas Akwẽ-Xerente. Para esta discussão, foram analisadas as pesquisas já realizadas em aldeias indígenas (AVELAR, 2014; RAMOS, 2016; OLIVEIRA, 2016; MOREIRA, 2017), em que são mencionados os diversos problemas de execução e acesso ao programa, assim também como foram abordadas as melhorias que o benefício condicionado trouxe para a realidade social dos indígenas. Esses estudos foram comparados com os dados coletados na pesquisa de campo entre os Xerente e nos mostram que as melhorias, dificuldades e impactos do PBF entre os indígenas brasileiros são semelhantes.

Os (as) Akwẽ-Xerente, que se autodenominam Akwẽ e são classificados na etnologia como Jê Centrais, vivem no município de Tocantínia - TO, a $76 \mathrm{~km}$ da capital do estado do Tocantins, nas Terras Indígenas (TIs) Funil e Xerente, entre o rio Tocantins, margem esquerda, e rio Sono, margem direita. São do tronco linguístico Macro-Jê, da família Jê, e sua língua materna é o $A k w e \tilde{e}$ São contabilizadas 81 aldeias, possuindo seis postos de saúde e 3.350 habitantes, sendo $1.689(50,42 \%)$ do sexo masculino e 1.661 (49,58\%) do sexo feminino.

Este artigo é resultado de uma pesquisa realizada no âmbito do Programa de PósGraduação em Desenvolvimento Regional, da Universidade Federal do Tocantins, e corresponde à dissertação de mestrado "Políticas públicas e povos indígenas: uma análise do impacto do programa bolsa família entre os Akwẽ-Xerente". A pesquisa de campo ocorreu em duas aldeias Xerente, entre os meses de setembro a dezembro de 2018, com o intuito de observar os impactos que o PBF trouxe para a realidade social dos indígenas. Além da observação, foram realizadas vinte e oito entrevistas semiestruturadas com as famílias beneficiadas, duas entrevistas com técnicos que atuam na política de assistência social do município, duas com técnicos da saúde indígena ${ }^{3}$ e uma com liderança indígena. Para análise dos dados foram usados os registros feitos no caderno de campo e as entrevistas transcritas.

As aldeias escolhidas para a pesquisa de campo foram a aldeia Funil e a aldeia Porteira, a primeira localizada na TI Funil e a segunda na TI Xerente. A aldeia Funil está localizada a onze quilômetros de Tocantínia. Nela vivem sessenta famílias, totalizando trezentas pessoas. Tem um posto de saúde que atende também seis aldeias próximas, uma escola e uma igreja católica. A aldeia Porteira está localizada a vinte quilômetros de

\footnotetext{
${ }^{3}$ É válido destacar que um dos técnicos que atuam na política de assistência social é Akwẽ-Xerente, assim como os dois técnicos da saúde indígena.
} 
Tocantínia - TO, nela vivem 90 famílias, totalizando 500 pessoas. Tem um posto de saúde que atende vinte aldeias próximas, uma escola e uma Igreja Batista.

\section{Os Xerente e o Programa Bolsa Família}

Para analisar o impacto do PBF entre os povos indígenas buscou-se identificar quais as melhorias que esse programa trouxe para as famílias indígenas; o que costumam comprar com o dinheiro; como ocorre o acompanhamento das condicionalidades; se o programa interferiu na estrutura patrilinear da cultura Xerente; como a mulher se sente sendo a titular do cartão; como ocorre o acompanhamento do CRAS na área indígena; o que os (as) indígenas acham que deveria melhorar no PBF; e qual a percepção deles sobre o Programa. Os principais problemas relatados nas pesquisas já realizadas em aldeias são sobre a inflexibilidade das condicionalidades, endividamento no comércio local e a falta de entendimento sobre o papel de cada órgão envolvido na execução do Programa (AVELAR, 2014; RAMOS, 2016; OLIVEIRA, 2016; MOREIRA, 2017).

Os Akwẽ-Xerente da Aldeia Funil e Porteira consideram que o PBF melhorou a vida deles, muitos relataram que antes do programa eles trabalhavam muito, ficavam até tarde fazendo artesanato para conseguirem comprar o que faltava em casa. As mulheres continuam fazendo artesanato e indo até a cidade vender, até porque elas consideram que o PBF garantiu, em certa medida, condições melhores de vida, mas precisam complementar a renda, pois o dinheiro é insuficiente para comprar tudo que precisam.

Em uma entrevista, foi relatado que antes do PBF havia um programa estadual intitulado "Tocantins Sem Fome", operacionalizado por meio de entregas de cestas básicas. Os (as) entrevistados (as) consideraram que é melhor receber o dinheiro do Bolsa Família, pois podem comprar calçados, roupas e materiais escolares para as crianças, além dos alimentos. No tocante aos benefícios que o programa trouxe para os indígenas, eles (elas) relataram que:

Ajuda muito, é pouco, mas dá para ajudar (INDÍGENA 1).

\footnotetext{
4 "O Programa Tocantins Sem Fome é composto de projetos e ações que combatam a fome e promovam a segurança alimentar e nutricional, nas modalidades de transferência de crédito e renda". Notícia publicada no site da Secretaria de Trabalho e Assistência Social (SETAS) no dia 24/4/2012, acesso em: 31 dez. 2018.
} 
Melhorou muito. Faltava muita coisa, que só do artesanato não dava. Agora
compro alimentos e materiais escolares (INDÍGENA 11).
Ficou melhor né? Quando não tem dinheiro, tem Bolsa Família, né? Faço
artesanato, mas vende pouco, né? Com o Bolsa Família, melhorou muito
(INDÍGENA 13).
Melhorou a alimentação. Compro alimentos e materiais escolares para os meninos
(INDÍGENA 17).

As pesquisas realizadas em aldeias indígenas apontaram que o recurso tem possibilitado a garantia da sustentabilidade alimentar da população, seja pela compra de alimentos, seja pela compra de ferramentas para o plantio. Os (as) entrevistados (as) relataram que costumam comprar arroz, feijão, carne, frango, óleo, sal, açúcar, sabão, caderno, caneta, lápis, borracha, gás e material para o artesanato. Uma entrevistada considera que o programa possibilitou às mulheres o acesso à compra de materiais para fazer artesanato, abriu a mente delas em relação a isso.

Sobre o destino do recurso recebido pelos indígenas, as pesquisas apresentaram, na maioria dos casos, o discurso de que o dinheiro é para as crianças irem para a escola. Também destinam o recurso para comprar alimentos complementares, ou seja, aqueles que não são produzidos nos roçados (AVELAR, 2014; BRASIL, 2015; RAMOS, 2016; OLIVEIRA, 2016; MOREIRA, 2017). Em alguns casos, o recurso é utilizado somente para a compra de comida: "Isso ocorre nas situações em que a família não tem um roçado suficientemente produtivo, nem recebeu cesta básica compatível com o tamanho da família" (BRASIL, 2015, p. 8).

Um fato importante observado por Ramos (2016) é sobre a associação do benefício com a compra de bebidas alcoólicas. Na pesquisa dessa autora, as indígenas não associavam o benefício com esse tipo de gasto. Elas mencionaram que os consumidores de bebidas alcoólicas são homens que trabalham na aldeia (plantação e pesca), os quais vendem seus produtos e gastam o dinheiro com bebidas alcoólicas e/ou drogas. Entre os Xerente, as mulheres consideravam importante o cartão ser em nome delas, pois assim garantem que ele seja usado para o benefício da família. 
Brasil (2015) apresenta estudos de casos em sete Tls $^{5}$ a fim de compreender e aprimorar a execução do PBF para os povos indígenas. O estudo identificou que em todas as aldeias há a problemática sobre o intitulado "patrão", que são os comerciantes locais, que ficam com os cartões para recebimento dos benefícios dos indígenas: "em todos os casos relatados eles são comerciantes locais, que providenciam transporte (pago) para o acesso aos locais de saque do recurso do PBF, e que orientam os indígenas a gastar o dinheiro nos seus estabelecimentos comerciais" (BRASIL, 2015, p. 7). Esses "patrões" ficam com os cartões como garantia do pagamento de dívidas contraídas pelos indígenas. Além dos comerciantes, os funcionários das Casas Lotéricas também aproveitam da dificuldade dos indígenas de manuseio do sistema de cartão magnético, para se apropriarem do valor do benefício.

O fato do Bolsa Família possibilitar crédito aos seus beneficiários reproduz a ideologia da "facilitação" que, em virtude da desinformação dos indígenas sobre o programa, faz com que estes associem os comércios e as lotéricas como parte da gestão do PBF, reproduzindo sistemas de exploração e dominação das populações indígenas: "uma das pesquisadoras constatou que a falta de alternativas de transporte e o seu custo relativamente elevado deixam os indígenas a mercê dos "patrões", que retêm seus cartões ou documentos pessoais quando se endividam" (BRASIL, 2015, p. 15).

Silva (2005) também fala sobre a apropriação dos cartões do Bolsa Família pelo comércio local, possibilitando crédito aos beneficiários, mas também "transformando esses usuários não em cidadãos, mas em escravos e dependentes para manter sua sobrevivência, mediante a exploração, senão do trabalhado, mas de sua própria cidadania" (p. 273).

Na realidade Xerente, somente dois entrevistados falaram sobre isso, todos (as) os (as) outros (as) afirmavam que o cartão ficava com eles (elas). Isso pode estar relacionado ao fato de que o CRAS realizou uma reunião com os comerciantes orientando-os sobre essa questão. Imagina-se que ou os comerciantes devolveram os cartões para os (as) beneficiários (as) ou condicionaram para sempre falarem que os cartões não ficam nos comércios locais. Uma das entrevistadas explicou que: "o armazém não confia no indígena.

\footnotetext{
5 Terra Indígena Barra Velha; Terra Indígena Porquinhos; Terra Indígena Takuaraty/Yvykuarusu (ou Aldeia Paraguasu); Terra Indígena Dourados; Terra Indígena Alto Rio Negro; Terra Indígena Parabubure; e Terra Indígena Jaraguá.
} 
Aí o cartão é como garantia. Eles aumentam o valor por conta do prazo. O mercado cobra $5 \%$ de juros. A maioria dos indígenas deixa o cartão lá para fazer "as compras adiantado" (INDÍGENA 24).

Sobre o valor dos produtos do comércio local, muitos dos (as) entrevistados (as) enfatizaram o preço elevado. Eles acham que o comércio cobra mais caro para os indígenas: "o armazém aumenta o preço da compra. Uma vez eu fiz os cálculos. Eles passam as pernas" (INDÍGENA 15). A equipe técnica do CRAS interpreta esse processo da seguinte forma: "muitos indígenas, pela falta de conhecimento, deixam os cartões nos estabelecimentos. Os comerciantes cobram mais caro deles. Colocam um preço mais alto para os indígenas, por conta do prazo que dão" (TÉCNICO 1).

Além disso, a pesquisa de Brasil (2015) apontou ainda a dificuldade que muitos indígenas têm para sair das aldeias e irem à cidade sacarem o benefício, enfrentam situações de constrangimento onde sacam e gastam os recursos: "no caso de uma das Tls pesquisadas, os constrangimentos envolvem as mulheres e crianças, que seguem até os locais de saque com elas, que muitas vezes esperam por horas na fila do caixa para serem atendidas" (BRASIL, 2015, p. 8). Nas aldeias Xerente, onde foi realizada a pesquisa, esse não é um grande problema. Os (as) indígenas vão para a cidade no ônibus coletivo usado no transporte escolar. Alguns têm moto e, como as aldeias são bem próximas de Tocantínia TO, o acesso é fácil. Mas há de considerar que há aldeias mais distantes, cerca de $80 \mathrm{~km}$ da cidade, para esses indígenas o acesso é mais complicado. Nenhum dos entrevistados reclamou sobre o atendimento da lotérica ou Caixa Econômica Federal.

No que se refere às condicionalidades, a pesquisa realizada por Brasil (2015) mostrou que os indígenas parecem não saber bem a intenção de certas condições. Sobre a freqüência escolar, eles relataram dificuldades operacionais, como falta de transporte para levar as crianças para escola, falta de capacitação de professores e também de um sistema de freqüência que funcione nas escolas. Em relação às condicionalidades de saúde, a pesquisa apresentou que as equipes não buscam realizar ações para resolver as deficiências e vulnerabilidades apresentadas por meio do atendimento de saúde:

Isso acaba contribuindo ainda mais para a compreensão geral que apareceu por praticamente todos os casos investigados: a de que as condicionalidades são uma "tarefa" ou um "pedágio", em muitos casos algo bastante oneroso, que os 
beneficiários têm de realizar ou pagar para viabilizar e garantir a continuidade do acesso ao benefício. Em algumas das terras investigadas houve reclamações graves sobre a qualidade dos serviços prestados pelo sistema de saúde (BRASIL, 2015, p. 7).

Entre os Xerente há a ciência da necessidade de levar a criança para o Posto de Saúde todos os anos e comprovar a freqüência à escola, através de uma declaração que deve ser entregue ao CRAS. Não citaram nenhuma dificuldade em cumprir essas condicionantes: "a gente nunca teve o cartão bloqueado por conta da saúde e da escola não. O Postinho faz acompanhamento certinho" (INDÍGENA 4). Alguns afirmam que antes do Programa as crianças não eram assíduas à escola: "é melhor, pois agora a criança tem que ir para a escola, antes criança trabalhava na roça. Agora a criança tem que estudar. Isso foi bom" (INDÍGENA 23).

Observou-se que o programa contribuiu para a segurança alimentar entre os Xerente. Várias mulheres relataram que antes do PBF dedicavam muitas horas ao artesanato, para comprar alimentos. Algumas afirmaram que sentem dores nas mãos causadas pela pelo esforço repetitivo e outras mencionaram dores na coluna e problemas de visão. A ideia, muito difundida, de que o PBF deixou as pessoas preguiçosas, também é reproduzida entre os Xerente: "o Bolsa Família é bom para aqueles que não têm condições de trabalhar. Só que tem indígena que confia no dinheiro do Bolsa Família e não quer fazer nem roça mais" (INDÍGENA 24). O técnico da saúde indígena também falou um pouco sobre essa questão:

Muitos falam... muitos comentam que... até vem dos não indígenas, que moram próximos nas cidades vizinhas... Eles falam muito que o índio ficou preguiçoso, que ele não planta, que índio não faz isso mais que fazia e tal porque tem o Bolsa Família. Que o governo federal devia tirar o Bolsa Família dessas pessoas para eles trabalharem com roça de toco, roça mecanizada, fazer suas próprias comidas, plantio e tudo mais... (TÉCNICO 2).

Durante a pesquisa de campo não foi identificado um possível comodismo por parte das beneficiárias em razão do benefício. Em todos os dias em que a pesquisa de campo foi realizada as mulheres estavam trabalhando em suas casas, os homens tinham ido para a roça ou estavam em outras atividades como construção de casas ou limpeza de terrenos. No final da manhã, alguns chegavam com mandioca e outros legumes. 
Pesquisadores como Tavares (2010), Cavalcanti et al. (2016) e Santos et al. (2017) discutem o chamado efeito preguiça associado ao PBF. Para Tavares (2010), o PBF pode gerar redução na renda da família uma vez que alguns membros podem deixar de trabalhar ou reduzir as horas de trabalho, resultando em dedicação de mais tempo para a família e qualidade de vida. Desse modo, essa pesquisadora desenvolveu um estudo para avaliar se o programa contribui no incentivo adverso à oferta de trabalho das mães beneficiadas e destacou que:

Quando se avalia o impacto de cada real transferido sobre as decisões de trabalho das mães beneficiárias, nota-se que os coeficientes da variável que indica o valor do benefício recebido são significantes e negativos, o que implica que tanto a participação no mercado quanto a jornada de trabalho das mães beneficiárias diminuem à medida que o valor da transferência aumenta. Esses resultados parecem contradizer o mito do 'efeito-preguiça' (TAVARES, 2010, p. 628).

Tavares (2010) nos mostra que o efeito positivo de participação das mães no programa está relacionado à obrigatoriedade de os filhos freqüentarem a escola. Isso proporcionou às mães mais tempo livre para desenvolverem atividades remuneradas. Além disso, os filhos, que antes trabalhavam, agora têm que ir para a escola, fazendo com que as mães tenham que trabalhar mais para não diminuir a renda da família. No entanto, quanto maior o valor recebido pela família pode ocorrer o incentivo adverso ao trabalho, ou seja, o efeito-renda pode ser a causa do efeito-preguiça. As mães podem optar por dedicar mais tempo aos filhos e reduzir sua oferta de trabalho, o que se analisa como um ponto positivo, pois com o benefício, as pessoas podem fazer escolhas, ter mais qualidade de vida, podem sair do trabalho informal e precário, podem negociar condições mais justas de trabalho, sem vínculos fracos e com salários justos.

Cavalcanti et al. (2016) considera que as condicionalidades são mais importantes do que a própria transferência de renda, pois possibilita acesso à saúde, educação e superação do trabalho infantil. Todavia, alguns autores criticam a exigência de contrapartida por parte do Estado, pois, com isso, penaliza as famílias mais vulneráveis. O descumprimento das condicionalidades faz com que os beneficiados sofram advertências, mas exige que os órgãos responsáveis façam o acompanhamento a essas famílias. Um dos pontos destacados pelos pesquisadores está relacionado ao fato de que as pessoas não deixaram de trabalhar em ofícios aos quais se dedicavam antes de receber o auxílio do PBF. Optaram, no entanto, 
por dedicar mais tempo à família e à casa. Para Tavares (2010), Cavalcanti et al. (2016) e Santos et al. (2017), o PBF pode também estar associado ao fato de os beneficiários preferirem trabalhos informais:

\begin{abstract}
Acredita-se, ainda, em uma possível fuga de contratos formais, o que justificaria o não impacto do PBF na jornada de trabalho entre aqueles que ofertam $20 \mathrm{~h}$ e $40 \mathrm{~h}$ semanais de labore. Além disso, pode ser que beneficiários do PBF sejam lotados em trabalhos menos remunerados, e com isso verifica-se impacto negativo na renda do trabalho (CAVALCANTI et al., 2016, p. 198).
\end{abstract}

Para os Xerente o trabalho não é uma atividade que deve ocupar a totalidade do cotidiano do grupo. As atividades produtivas devem respeitar o equilíbrio entre os seres visíveis e invisíveis que habitam o território, como citado por Silva e Grácio (2020, p. 137):

Para a cosmologia Akwẽ, o território é um espaço compartilhado por seres visíveis e invisíveis que, assim como os humanos, estabelecem relações sociais e produtivas que devem ser reconhecidas e respeitadas. Para todos esses seres há espaços e alimentos disponíveis, assim como formas de obtê-los. Cada coletividade deve respeitar o que é "de comer" de cada grupo, assim como os espaços de cada um. Cada espécie e espaços naturais têm os seus donos, denominados tdekwas. Estes se relacionam cotidianamente com os humanos. (...). Os tdekwas se comunicam com os Akwẽ quando identificam uma atividade que pode ameaçar o equilíbrio do espaço compartilhado, a exemplo da pesca em excesso. A perspectiva é a de que o território é um todo e que o seu equilíbrio depende do respeito a acordos de convivência, muitos deles associados às atividades produtivas como a caça, a pesca, a coleta e a agricultura.

É possível apontar que a perspectiva de trabalho da maneira como a sociedade nacional a compreende, intrinsecamente vinculada ao modelo capitalista de produção, não é compartilhada pelos Xerente, apesar dos mais de trezentos anos de contato sistemático. Nesta direção não é possível compreender a relação desse povo com o trabalho a partir dos mesmos parâmetros aplicados aos beneficiários não indígenas.

Valdete Xerente (2015), em pesquisa sobre o impacto do Programa Bolsa Família nas TIs Xerente, constatou que as mulheres entrevistadas continuam fazendo as atividades de artesanato e ajudando nas roças dos maridos, o que também pudemos atestar durante a inserção em campo. O PBF possibilitou autonomia para as mulheres Xerente, ao permiti-las 
escolher o que é prioridade para a família, assim como subsidiar a compra de medicamentos não fornecidos pelo órgão responsável pela saúde indígena.

\section{O Centro de Referência da Assistência Social (Cras) e os Xerente}

Brasil (2015) verificou que o repasse de recursos financeiros é bem aceito entre as populações indígenas. Eles definem o dinheiro repassado pelo PBF como o "dinheiro das crianças" ou "dinheiro das mulheres". Os pesquisadores constataram que os indígenas têm pouco conhecimento do programa em relação aos órgãos responsáveis, às regras e objetivos. Muitas vezes, eles procuram informações sobre o programa em casas lotéricas ou até mesmo com os comerciantes das cidades no entorno da TIs.

Os estudos de Avelar (2014) e Ramos (2016) apresentaram que um dos grandes impasses do PBF é o acompanhamento por parte da Assistência Social. Um número significativo de indígenas menciona que não sabem sobre o CRAS, muito menos sobre os serviços ofertados por este órgão. Quando têm conhecimento da Equipe Volante ${ }^{6}$, que às vezes comparece às aldeias, relatam que a freqüência das visitas é pequena e sem um atendimento contínuo. Os caciques que entendem a importância do trabalho da política de assistência social junto às comunidades indígenas reivindicam esses serviços, mas nem sempre são atendidos.

Na pesquisa de campo foi percebido que a atuação do CRAS é um dos grandes problemas apontados pelos (as) indígenas, eles relacionam essa atuação com o cadastramento, atualização do cadastro e bloqueio do benefício. Todos sabem que é o CRAS o responsável pelas informações relacionadas ao PBF. Identificamos que, quando elas não têm o benefício bloqueado, consideram que o CRAS faz um bom trabalho, atendendo bem os (as) indígenas. Mas quando já tiveram o benefício bloqueado uma vez, relatam que o CRAS não atende bem:

\footnotetext{
${ }^{6}$ A Equipe Volante integra a equipe do CRAS e tem o objetivo de prestar serviços de assistência social a famílias que residem em locais de difícil acesso (áreas rurais, comunidades indígenas, quilombolas, calhas de rios, assentamentos, dentre outros).
} 
O CRAS atende bem, mas naquele tempo que deu errado, não atenderam bem. Agora atende bem. Uma vez bloqueou, pois, meu marido recebe aposentadoria. Mas não entendi, pois, meu filho estuda na cidade (INDíGENA 16).

No CRAS, atende ruim, bloqueou e não explicou. Eles não explicam nada e fica bloqueando. Tá bloqueado esse mês. O povo de lá, não gosta dos índios. Seria bom eles vir aqui e ver que os filhos estão estudando (INDÍGENA 19).

Eles humilham demais a gente. Ficam falando que meu marido está trabalhando. Dos brancos eles não cortam não, que eu sei (INDÍGENA 20).

Os bloqueios ocorrem devido à realização de atividades remuneradas por parte dos indígenas sem atualização no cadastro. Alguns indígenas conseguem emprego nas escolas das aldeias ou na saúde indígena. Além disso, existem alguns (as) que recebem o Benefício de Prestação Continuada (BPC), todas essas rendas, quando não informadas, podem ocasionar o bloqueio do benefício, conforme explica a assistente social do CRAS: "eles também não têm o conhecimento que se o marido está trabalhando e está recebendo só um salário mínimo e existem seis pessoas, eles não perdem o benefício. Mas tem que atualizar, por isso bloqueia" (TÉCNICA 1). Desse modo, a equipe do cadastro informa sobre o perfil do programa, mas muitos (as) indígenas não compreendem:

Têm muitos indígenas que não entendem sobre o perfil. Eles acham que só por serem indígenas, eles têm direito ao PBF. Têm indígenas que têm renda acima do perfil. Eu explico para fazer desligamento voluntário. Eles não aceitam. Daí depois o MDS corta e quando eles perdem a renda, não conseguem serem inseridos tão rápido (TÉCNICA 3).

O CRAS de Tocantínia - TO foi implantado em 2009. Anteriormente, o cadastramento do PBF ficava sob responsabilidade da Secretaria Municipal de Assistência Social. Atualmente a equipe do cadastro fica no CRAS, mas são papéis e responsabilidades diferentes. O papel do CRAS é prevenir situações de risco e vulnerabilidade social nos territórios. O público prioritário são pessoas beneficiárias de alguma política de assistência social, promovendo o acompanhamento social a essas famílias e prevenindo a fragilização dos vínculos familiares ou com a comunidade. No entanto, observamos que os assistentes sociais do CRAS de Tocantínia, não recebem formação adequada para atuar junto aos Xerente, considerando suas especificidades étnicas e históricas. Não há visitas frequentes às aldeias e as palestras de orientação ocorrem somente no âmbito do CRAS:

Nunca veio assistente social na área. Uma vez eu fui lá e falei: Vocês que trabalham no CRAS, não conhecem a realidade de quem está na aldeia. Vocês não saem, é obrigação de vocês ir às aldeias fazer palestras. Nas aldeias, nós não vivemos como 
vocês que estão na cidade, não. Vocês não podem ver sol, só querem ficar no ar condicionado. Tem Aldeia que dá $50 \mathrm{~km}$ da cidade, e nós temos que ir ao CRAS (INDÍGENA 2).

O CRAS nunca veio para conhecer nossa realidade. Acho que seria bom. Eles só cortam e não explicam. Muitos estão sem receber. $O$ pessoal corre atrás das declarações, chegam lá, eles não atualizam (INDíGENA 11).

É importante ressaltar que o CRAS não dispõe de uma Equipe Volante, dificultando a realização de um acompanhamento contínuo das famílias que moram na fora da zona urbana. Somente as indígenas entrevistadas na aldeia Porteira afirmaram que o CRAS compareceu à aldeia para fazer o cadastramento das famílias em 2003. Os indígenas da Aldeia Funil disseram que o CRAS nunca foi até a área indígena. Em diversas conversas, eles mencionavam que ninguém procura conhecer a realidade deles, que os moradores de Tocantínia - TO não gostam de índios: "a gente gosta de conhecer o povo que vem conhecer a realidade e ajudar. A gente não gosta de pessoas que vem, faz promessas e depois some" (INDÍGENA 4).

Uma das dificuldades apontadas pelos (as) indígenas é que muitas vezes se deslocam até a cidade, chegam ao CRAS e o sistema está fora do ar, tendo que se deslocar novamente em outro dia para fazer a atualização cadastral: "a gente vai lá no CRAS e, às vezes, não tem internet. Daí tem que voltar outro dia" (INDíGENA 24). A gestora do PBF informou que a equipe vai à aldeia quando há descumprimento das condicionalidades. Perguntamos como ocorrem as visitar e com que freqüência e a equipe explicou que é por meio de busca ativa, quando alguém informa sobre uma família em vulnerabilidade social, ou por demanda espontânea, quando a própria família procura o CRAS. Sobre a entrada nas aldeias explicaram:

Nós mandamos ofício para o cacique, aguardamos a resposta e vamos. Nem todos aceitam nossa entrada. Teve uma vez que fui com uma Xerente, eu não sabia, mas tinham uma rivalidade com ela, daí o cacique não deixou eu entrar naquela aldeia. Mas só depois fui entender (TÉCNICA 3).

As dúvidas dos indígenas em relação ao PBF estão relacionadas à renda, ao motivo dos bloqueios e ao fato de uma família receber mais que a outra. Essas dúvidas poderiam ser esclarecidas por meio de um acompanhamento social e até mesmo realização de palestras de orientação nas aldeias: 
Às vezes, a equipe fala para eles ou, às vezes, a pessoa não está informada, não consegue chegar à aldeia, por exemplo, para falar dessa informação. A dificuldade que eles têm também de vir para um evento que acontece aqui dentro do CRAS... e a maioria.... a maioria, não, todas moram na aldeia, algumas delas já moram na aldeia mais longe, mais distante daqui de Tocantínia e essa dificuldade de vir para as reuniões e as informações não chegam até todas (TÉCNICA 1).

Observou-se que as palestras de orientação ou cursos ocorrem somente no CRAS, algumas reuniões já aconteceram nas aldeias, separadas por regionais, mas não é uma ação contínua. Os (as) indígenas entrevistados (as) se queixam muito da ausência do CRAS na área indígena, por isso, a equipe da Assistência Social explica sobre a ausência dessa ação:

\begin{abstract}
Algumas vezes sim... Mas, é como eu falei anteriormente, é mais aqui no CRAS, a gente tem dificuldade para eles vir aqui, mas a gente não leva para a reserva indígena, não tem essa ação. Não tem diretamente para a reserva indígena, até porque a gente não tem aquele CRAS volante, pois facilitava muito (TÉCNICA 1).
\end{abstract}

As principais dificuldades que a equipe da Assistência Social tem em relação ao atendimento aos povos indígenas estão relacionadas à língua: "já teve atendimento de eu ficar a manhã inteira e não entender nada. Ainda bem que contamos com a ajuda de alguns indígenas" (TÉCNICA 3). E mesmo tendo indígenas na equipe ${ }^{7}$, percebeu-se que a língua continua sendo um ponto de dificuldade:

A linguagem. Por que a maioria. Sempre falar a maioria, porque assim... Os indígenas, as mães que não teve estudo, elas falam o português, mas não entendem o que vocês falam. O português completo, né? Ás vezes, entende... mas... Por exemplo, condicionalidades, se eu falar pra elas, elas não vão entender. Então...o que elas entendem é só sacar o benefício, colocar a criança na escola, tem que vacinar, tem que está com frequência em dia, tem que pesar as crianças, elas entendem. O que é condicionalidades, elas não vão entender (TÉCNICA 1).

Sobre a abordagem dos profissionais que trabalham no cadastro, alguns (as) indígenas sentem-se constrangidos em responder as perguntas provenientes do Cadastro Único, que, em certa medida, não estão relacionadas com a realidade social deles: "o pessoal do CRAS faz muitas perguntas, me sinto constrangida. Perguntam se temos casa. Até onde fazemos coco eles querem saber. Se queimamos o lixo. Como fazemos comida. Acho que perguntam demais" (INDÍGENA 8). Outros indígenas gostam de responder as perguntas:

\footnotetext{
${ }^{7}$ A indígena que compõe a equipe do CRAS é assistente social, entretanto, no período de realização das entrevistas, o município de Tocantínia-TO havia realizado concurso público e seu contrato de trabalho estava nos últimos meses. Ela relatou que além dela, havia mais dois indígenas Akwẽ-Xerente na Secretaria de Assistência Social do município.
} 
"eu gosto de responder as perguntas lá do CRAS. Perguntam se as crianças estão estudando. Estão preocupados, né? Perguntam o que a gente compra. A gente compra comida e material escolar" (INDÍGENA 24).

Em relação a isso, entende-se que a forma de falar pode fazer diferença, muitos (as) entrevistados (as) relataram que existem pessoas na equipe do cadastro que explicam bem e que atendem bem, contudo, outras nem tanto. Essas questões poderiam ser aprimoradas por intermédio de capacitações específicas para o atendimento dos povos indígenas. Sobre isso, questionamos se a equipe já passou por este tipo de capacitação:

Participamos de várias capacitações promovidas pela Secretaria Estadual de Assistência Social (SETAS) sobre o Bolsa Família, nenhuma específica sobre o atendimento aos indígenas. Mas, em algumas, mencionam sobre o atendimento aos povos indígenas e a temática indígena (TÉCNICA 3).

Em relação à operacionalização do programa e o acompanhamento das famílias beneficiadas, Rodrigues (2016) aborda que a introdução de dinâmicas de consumo no meio indígena, por meio de transferência de renda, sem um processo de escuta de suas necessidades acaba desqualificando os programas sociais. O processo de trabalho social com as famílias indígenas deve valorizar suas formas de organização socioeconômica, compreendendo a diversidade étnica de cada povo.

Para a inserção dos povos indígenas em programas sociais, conforme Rodrigues (2016) é importante conhecer sua realidade social, uma vez que muitos têm modos de viver e hábitos alimentares diferentes do restante da sociedade. É importante também avaliar os impactos da inserção em programas sociais na vida dos povos indígenas. Outro fator mencionado pela autora são as condições sócio-ambientais dos territórios indígenas, associadas aos projetos de desenvolvimento, que intensificam o esgotamento da caça, pesca e poluição dos rios. Desse modo, muitos desses povos só conseguem garantir sua segurança alimentar por meio de intervenção do poder público, como apresentamos a seguir.

\section{O Programa Bolsa Família e a Segurança Alimentar Indígena}

Os impactos econômicos, sociais e culturais dos empreendimentos de desenvolvimento implantados na região do Tocantins afetaram o modo de vida dos 
indígenas. Alguns relataram que a alimentação mudou no decorrer dos anos, constatou-se que isso não está diretamente relacionado com os programas de transferência de renda, mas à escassez de caça e pesca na região: "nós temos Lajeado perto, Tocantínia, Palmas. Onde vai ter caça na aldeia?" (INDÍGENA 2).

Conforme Silva e Grácio (2020), os projetos de desenvolvimento econômico têm um impacto direto nas relações tradicionais dos povos indígenas com o seu território. No caso dos Akwẽ-Xerente a Usina Hidrelétrica Luis Eduardo Magalhães (UHE de Lajeado), mudou o fluxo do rio Tocantins, não permitindo mais o plantio tradicional nas chamadas vazantes. Essa prática milenar era amplamente utilizada pelo povo Xerente e pelos ribeirinhos do rio Tocantins, que utilizavam as margens férteis do rio, quando o nível das águas estava baixo, para plantar uma grande variedade de alimentos. Os pesquisadores apontam que antes da UHE havia mais de trezentas famílias Xerente que se sustentavam com os alimentos das roças de vazante.

Para esses autores, os Akwẽ-Xerente vivenciaram profundas alterações nas suas práticas tradicionais de caça, pesca, coleta e plantio, uma vez que a pressão dos projetos de desenvolvimento incide diretamente sobre os rios, solo, fauna e flora das Tls. Ao mesmo tempo que o PBF possibilita a aquisição de alimentos no cenário de impactos citado, ele também contribui para o aumento do consumo de produtos alimentícios industrializados de baixo valor nutritivo e alto valor calórico, que contribui para o aparecimento das doenças crônicas não transmissíveis, como diabetes tipo dois e hipertensão arterial.

Essas mudanças também são citadas por Xerente (2015). A autora apresenta que a alimentação dos Xerente mudou muito, antes se alimentavam do que produziam nas lavouras, do que coletavam de frutos e do que caçavam na mata:

\footnotetext{
Os temperos utilizados no cozimento das carnes eram a base de pimenta de macaco (encontrada na mata), erva semelhante à pimenta do reino e o óleo de cozinha era feito de coco de babaçu. A sobrevivência era por meio da caça, pescam, frutos, raízes e na plantação na roça de toco (XERENTE, 2015, p. 40).
}

Xerente (2015) afirma que as mulheres Xerente trabalhavam com a quebra de cocos de babaçu, vendiam os cocos quebrados em Tocantínia - TO, por preços muito baixos, com o dinheiro que ganhavam, compravam alimentos e peças de roupas. Importante essa percepção da pesquisadora, pois isso nos mostra que as mulheres sempre buscavam 
alternativas para complementar a alimentação da família. Atualmente, as mesmas complementam com o que ganham do artesanato que vendem e do valor que recebem do PBF. Se essa alteração da alimentação é anterior ao programa, temos que analisar se a mesma garante a segurança alimentar da família: "a gente come como vocês agora, antes não. Mas nossa alimentação mudou antes do Bolsa Família. Bem antes" (INDÍGENA 13). Xerente (2015) também aponta que o PBF contribui para o acesso à alimentação, no entanto, muitos indígenas passaram a comprar alimentos processados e industrializados, ocasionando problemas de saúde.

As mudanças nos hábitos de vida provocam mudanças na alimentação, e, de acordo com Salgado (2007), diminui a resistência física e deixa vulnerável às doenças. O autor faz referência às novas formas de produzir alimentos, adotadas nas últimas décadas pelos homens. Ele fala principalmente sobre a atuação na natureza, provocando a alteração dos biomas e impactando as terras e populações indígenas. As conseqüências dessas intervenções estão relacionadas, principalmente, à insegurança alimentar desse povo. Uma observação feita pelo autor é sobre o fato de grande parte das áreas preservadas no Brasil estarem localizadas em terras indígenas.

Os povos indígenas no Brasil vivenciam diversas transformações ambientais e socioeconômicas que os deixam em situação de vulnerabilidade alimentar e nutricional. A segurança alimentar está relacionada com a garantia da presença de alimentos em quantidade e qualidade para todas as pessoas de uma família (FÁVARO et al., 2007). Auzani e Giordani (2008) conceituam Segurança Alimentar e Nutricional como o acesso adequado e estável a alimentos de qualidade, sem prejudicar outras necessidades humanas. São práticas alimentares aceitas culturalmente, que promovem a saúde e estão inseridas no contexto social, ambiental e econômico da população. O conceito de segurança alimentar está relacionado ao acesso a alimentos em quantidade e qualidade, assim como acesso ao saneamento básico, serviços de saúde, educação, proporcionando qualidade de vida.

Na realidade Xerente, o foco desta pesquisa não foi analisar o nível de segurança alimentar entre eles, contudo, no decorrer do estudo, foi identificado que o PBF pode contribuir para garantir o acesso aos alimentos, diminuindo o risco de insegurança alimentar. Além disso, consta no II Plano Nacional de Segurança Alimentar e Nutricional 
(PLANSAN) como uma das metas a redução de $25 \%$ do déficit de peso de crianças indígenas menores de cinco anos acompanhadas nas condicionalidades do PBF.

As vinte e oito famílias entrevistadas relataram que costumam comprar os mesmos alimentos de uma dieta ocidental, como o arroz, feijão, açúcar, frango, carne, farinha, banana, temperos como sal e óleo. Os alimentos são preparados em um fogão no chão ou fogão a lenha. Alguns afirmaram que compram gás, mas outros se consideraram em uma posição privilegiada em relação aos não indígenas que vivem na zona urbana, pois podem cozinhar em fogão a lenha, não precisando comprar o gás. Com isso, percebe-se que os alimentos industrializados já fazem parte da dieta dos indígenas:

[...] o óleo de soja, o sal, o açúcar, o café, o pão e o biscoito, o macarrão, além dos refrigerantes estão entre os gêneros alimentícios mais comprados. Estes estudos têm demonstrado um certo padrão na incorporação das dietas tradicionais dos alimentos da sociedade envolvente (AUZANI; GIORDANI, 2008, p. 153).

Xerente (2015) identificou que os próprios indígenas associaram o Bolsa Família a doenças como hipertensão e diabetes: "O programa tem permitido, por outro lado, o acesso a alimentos processados e industrializados, com teor significativo de sal e açúcar, a exemplo dos refrigerantes e bolachas recheadas" (XERENTE, 2015, p. 54).

Em conversa com um dos enfermeiros da Saúde indígena, ele informou que os indígenas estão associando o programa com algumas doenças, pois antes não consumiam refrigerantes e coisas doces. Como muitos estão com medo de o PBF acabar, o profissional da Saúde indígena alertou que poderiam negar sobre a compra desses alimentos:

\footnotetext{
Essa questão de impacto do Bolsa Família entre o povo indígena é uma coisa que no entendimento do índio pode até anular. Assim a pergunta, porque eles já ouviram muito falar que, com esse programa Bolsa Família, as comunidades indígenas estão sofrendo alguns impactos, né? Tipo, por exemplo, impacto na saúde, em outras questões, né? Mas na saúde principalmente, questão cultural também, né? Tem esse impacto... Se essa pergunta for entendida de outro jeito pelos indígenas, eles não vão querer responder, não (TÉCNICO 2).
}

Em relação a isso, para Silva e Grácio (2020), os Akwẽ relacionam os problemas de saúde com a alimentação. Eles consideram que há alimentos para todos os seres, sendo 
seres materiais ou imateriais que habitam seu território. $\mathrm{O}$ alimento representa um elo entre as pessoas e seres:

No caso da relação com a sociedade não indígena, este elo tem sido avaliado como negativo, desestabilizador do equilíbrio do grupo, uma vez que a adoção dos hábitos alimentares dos "não índios" tem causado doenças, o acúmulo de lixo e poluição, fatores não existentes no período anterior ao contato (SILVA; GRÁCIO, 2020, no prelo).

O contato mudou a forma de produzir, ocupar o território e a própria alimentação. Mas, em certa medida, os indígenas ainda continuam com suas atividades tradicionais. Enfrentam novos desafios pela mudança ambiental, mas continuam plantando suas roças. Além disso, na aldeia Funil eles criam gado e porcos, herança do Programa de Compensação Ambiental Xerente ${ }^{8}$ (PROCAMBIX), o que nem sempre consideram como algo positivo: "a gente faz roça, mas o povo aí não. $\mathrm{O}$ gado e o porco comem tudo. O povo está matando os porcos, pois atrapalham demais. Eles comem até sabão e bombril. Comem tudo" (INDÍGENA 24).

O PBF garantiu acesso à alimentação, entretanto, nem sempre adequada, uma vez que falta orientação nutricional para as famílias beneficiadas. Não entendemos que o programa seja a causa de acesso a alimentos com baixo valor nutritivo, uma vez que as mulheres já vendiam seus artesanatos antes do PBF e tinham acesso aos alimentos comercializados nas cidades. Talvez isso seja resultado do contato com a cidade, a partir da venda de artesanato. E esse contato foi anterior ao programa: “Antigamente, a gente comia feijão da roça, caça, beiju. Agora, se oferecer para as crianças, nem comem. Agora só querem comer coisa da cidade" (INDÍGENA 25).

\footnotetext{
${ }^{8}$ O PROCAMBIX foi desenvolvido embasado nos resultados do Diagnóstico Etnoambiental das Terras Xerente e Funil, financiado pela Investco no ano 2000 e teve o objetivo de diminuir impactos ambientais diretos e indiretos junto aos indígenas, em decorrência da construção da hidrelétrica. Por meio do programa esperavase compensar impactos ambientais e preparar os indígenas para inserção e adaptação à nova realidade posta pelo desenvolvimento, envolvendo a comunidade indígena em todas as etapas do processo. Lima (2016) mostra que do projeto restam atualmente apenas carcaças de máquinas agrícolas e algumas cabeças de bovinos criados soltos, apesar do fato dos indígenas não gostarem dos gados, por destruírem suas roças. Com o fim do PROCAMBIX, os indígenas continuaram sofrendo as transformações ambientais causadas pela usina, assim como o avanço da urbanização e agronegócio na região. O PROCAMBIX, a exemplo de outros programas de compensação no Brasil, está inserido em uma lógica desenvolvimentista, em que a despeito dos prejuízos sociais, culturais e ambientais causados pelos grandes projetos de desenvolvimento, propõe intervenções descontextualizadas da realidade e do protagonismo das comunidades impactadas.
} 
Além disso, os indígenas, para continuarem produzindo suas roças, que garantem o acesso a uma alimentação tradicional, têm que cumprir as exigências dos órgãos ambientais: "quando vamos fazer roça de toco, temos que pedir autorização para os órgãos ambientais, ficou difícil" (INDÍGENA 1). Com a diminuição do território e da limitação das práticas de produção tradicionais e, até mesmo, burocratização dos órgãos ambientais, o PBF é uma das fontes de renda que tem possibilitado um acesso regular à alimentação e evitado situações de fome extrema e mendicância.

\section{Considerações finais}

Sobre a inserção de indígenas no PBF, vários problemas foram identificados por meio deste estudo, como a falta de efetividade nas políticas públicas que são exigidas como condicionalidades do programa, falta de preparo das equipes da Assistência Social para lidarem com os povos indígenas ${ }^{9}$, entre outros.

Para muitas famílias indígenas, o PBF é uma das únicas fontes de renda, possibilita a compra de alimentos, materiais escolares, roupas e materiais para o artesanato. A importância desse programa está relacionada com o acesso à educação e saúde aos povos indígenas, considerando que mulheres e crianças tinham que trabalhar ainda mais para complementar a alimentação. As crianças, por exemplo, tinham que ajudar na roça, sendo impossibilitadas de irem para escola ${ }^{10}$.

Em relação à segurança alimentar, não foi o programa que oportunizou o acesso a alimentos industrializados, essa mudança na alimentação é anterior à implantação do PBF. Claro que os (as) indígenas continuam comprando alimentos com baixo valor nutritivo, o que demanda a necessidade de orientação nutricional, assim como acompanhamento. Há de considerar que o programa garante o acesso à alimentação para muitos indígenas, uma vez que a caça está escassa, o rio é controlado pela hidrelétrica, diminuindo o fluxo de peixes e impossibilitando as roças nas vazantes.

\footnotetext{
9 Durante a pesquisa, foi relatado pela coordenadora do CRAS que não houve, por parte do MDS e da Secretaria Estadual, capacitações específicas para o atendimento aos povos indígenas.

${ }^{10}$ A Educação para os povos indígenas no estado do Tocantins está a cargo da Secretaria Estadual de Educação (SEDUC). Na área Xerente há 35 escolas indígenas (SEDUC, 2017). Quando não possui escola na aldeia onde a criança mora, ela vai de transporte escolar para a escola mais próxima.
} 
Os Xerente cobram muito a presença do CRAS nas aldeias para ouvir as necessidades e intervir em situações que são demandas da política de Assistência Social. É sabido sobre a falta da equipe volante no CRAS de Tocantínia - TO, problema grave para operacionalização da Assistência Social em uma cidade que tem uma população majoritariamente indígena e rural. $\mathrm{O}$ trabalho social junto às famílias indígenas permitiria resolver problemas como a falta de conhecimento sobre as condicionalidades, bloqueios indevidos, orientação sobre como gastar o benefício, sobre a posse do cartão, conflitos relacionados ao comércio local, como juros altos e preços das mercadorias alterados, assim como prevenir situações de riscos sociais e de vulnerabilidade, entre outras. Faz-se necessária a capacitação das equipes do CRAS para a compreensão e atendimento às especificidades culturais dos povos indígenas, bem como a incorporação de profissionais indígenas ao CRAS, o que tem ocorrido de maneira muito tímida, uma vez que a Universidade Federal do Tocantins tem formado assistentes sociais indígenas desde 2007.

Nesta direção, concluímos que as condicionalidades do PBF contribuem para evitar a exposição das crianças indígenas Akwẽ às ruas das cidades do entorno, e diminuem o trabalho infantil, bem como a vulnerabilidade associada a ele. Assim como todas as sociedades indígenas o povo Akwẽ vive um processo de intensas transformações, intensificadas pelo contato com a sociedade nacional e, principalmente, com a constituição do estado do Tocantins, em 1988. Como apontamos, os projetos de desenvolvimento impactam a sobrevivência desse povo e os desafia a elaborar e reelaborar constantemente a sua vida, suas relações e suas formas de habitar o território.

\section{Referências}

AVELAR, P. S. Programa Bolsa Família em Comunidades Indígenas Teréna. 2014. 120 f. Dissertação (Mestrado em Saúde e Desenvolvimento na região Centro-oeste da Universidade Federal de Mato Grosso do Sul).PPGSD-UFMS, Campo Grande, 2014.

AUZENI, S. C. da S.; GIORDANI, .R. C. F.. Inter-relações entre espaço físico, modo de vida Mbyá-guarani e alimentação na perspectiva da segurança alimentar: reflexões sobre a área indígena Araça-í em Piraquara/PR. Espaço Ameríndio, Porto Alegre, v. 2, n. 1, p. 129-165, jan./jun. 2008. Disponível em: inter-relações entre espaço físico, modo de vida mbyá-guarani e alimentação na perspectiva da segurança alimentar: reflexões sobre a área indígena araça-í em piraquara/pr | auzani | espaço ameríndio (ufrgs.br). Acesso em: 5 nov. 2018. 
BORGES, J. C.. Territórios recortados, políticas fragmentadas: a experiência da Assistência Social entre os índios Pataxó, Bahia. ACENO - Revista de Antropologia do Centro-Oeste, v. 3, n.6, p-211-227, ago/dez, 2016. Disponível em:

https://periodicoscientificos.ufmt.br/ojs/index.php/aceno/article/view/4295. Acesso em: 26 mar. 2018.

BORGES, J. C. "A sociedade brasileira nos fez pobres": assistência social e autonomia étnica dos povos indígenas. O caso de Dourados, Mato Grosso do Sul. Horizontes Antropológicos, Porto Alegre, Ano 22, n. 46, p. 303-328, jul/dez, 2016. Doi: https://doi.org/10.1590/S010471832016000200011. Disponível em: 0104-7183-ha-22-46-0303.pdf (scielo.br). Acesso em: 26 mar. 2018.

BRASIL. Ministério do Desenvolvimento Social. Estudos Etnográficos sobre o Programa Bolsa Família entre Povos Indígenas. Brasília, DF: MDS, Secretaria Nacional de Assistência Social, 2015. 18 p. Disponível em: https://fpabramo.org.br/acervosocial/estante/estudosetnograficos-sobre-o-programa-bolsa-familia-entre-povos-indigenas/. Acesso em: 18 mai. 2018.

BRASIL. Ministério do Desenvolvimento Social. Trabalho social com famílias indígenas na proteção social básica. Brasília, DF: MDS, Secretaria Nacional de Assistência Social, 2017. 74 p. Disponível em: miolo.web.indd (mds.gov.br). Acesso em: 22 mar. 2018.

CAVALVANTI, D. M. et al. Impactos do programa Bolsa Família na renda e na oferta de trabalho das famílias pobres: uma abordagem usando o efeito quantílico de tratamento. Economia Aplicada, São Paulo-SP, v. 20, n. 2, p. 173-201, 2016. Disponível em: Impactos do programa Bolsa Família na renda e na oferta de trabalho das famílias pobres: Uma abordagem usando o efeito quantílico de tratamento | Economia Aplicada (usp.br). Acesso em: 28 dez. 2020.

CAVALCANTI-SCHIEL, R. A política indigenista, para além dos mitos da Segurança Nacional. Estudos Avançados, v. 23, n. 65, p. 149-164, 2009. Disponível em: Ricardo.indd (scielo.br). Acesso em: 22 mar. 2018.

LIMA, L. G. B. Os Akwẽ-Xerente no Tocantins:

território indígena e as questões socioambientais. 2016. 320 f. Tese (Programa de PósGraduação em Geografia Humana). PPGGH/USP, São Paulo, SP, 2016.

MOREIRA, É. F. M.. Programa Bolsa Família: uma etnografia a partir da perspectiva das mulheres indígenas Ticuna. 2017. 87 f. Dissertação (Programa de Pós-Graduação em ciências sociais da Universidade do Vale do Rio dos Sinos). PPGCS-UVRS, São Leopoldo, RS, 2017.

OLIVEIRA, L. D. L. de. Estado e políticas públicas no vale do javari: os Kanamari e o Programa Bolsa Família. 2016. 129 f. Dissertação (Programa de Pós-Graduação em Antropologia Social da Universidade Federal do Amazonas). PPGAS-UFAM, Manaus, AM, 2016.

QUERMES, P. A. de A.; CARVALHO, J. A. de. Os impactos dos benefícios assistenciais para os povos indígenas: estudo de caso em Aldeias Guaranis. Ser. Soc. Soc., São Paulo, n. 116, 
p.769-791, out/dez, 2013. Disponível em: Revista116.indd (scielo.br). Acesso em: 26 mar. 2018.

RAMOS, C. M. P. Chinelos, mochilas e artesanatos: percepções sobre a contribuição do programa bolsa família em comunidades indígenas Pataxó do município de Porto Seguro/BA. 2016. 110 f. Dissertação. (Programa de Pós-Graduação em Ciências Sociais da Universidade Federal da Bahia). PPGCS-UFBA, Salvador, BA, 2016.

RODRIGUES, E. B. de O. O Programa Bolsa Família e suas condicionalidades para famílias indígenas aldeadas: breve extrato da realidade social dos beneficiários indígenas nas aldeias de Campo Grande/MS. 2016. 27f. Trabalho de Conclusão de Curso. Curso de Especialização Educação, Pobreza e Desigualdade Social. Disponível em: 02000517170.pdf (ufms.br). Acesso em: 3 mai. 2018.

SALGADO, C. A. B. Segurança alimentar e nutricional em terras indígenas. Revista de Estudos e Pesquisas, FUNAI, Brasília, v. 4, n. 1, p. 131-186, 2007. Disponível em: 05-Artigo-Carlos Salgado (funai.gov.br). Acesso em: 3 Nov. 2018.

SANTOS, D. B. et al. Os efeitos do Programa Bolsa Família sobre a duração do emprego formal dos indivíduos de baixa renda. Revista de Administração Pública, v. 51, n. 5, p. 708733, 2017. Disponível em: 1982-3134-rap-51-05-708.pdf (scielo.br). Acesso em 28 dez. 2018.

SILVA, M. O. S. e. Os programas de transferência de renda e a Pobreza no Brasil: superação ou regulação?. Revista de Políticas Públicas, São Luis, v.9, n. 1, p. 251-278, jul./dez 2005. Disponível em: os programas de transferência de renda e a pobreza no brasil: superação ou regulação? | silva | revista de políticas públicas (ufma.br). Acesso em: 16 dez. 2018.

SILVA, R. P.; GRÁCIO, H. R.. O modelo de desenvolvimento do Tocantins e o povo AkwẽXerente: impactos socioambientais e desafios da interculturalidade. Pracs: Revista Eletrônica de Humanidades do Curso de Ciências Sociais da UNIFAP. Macapá, v. 13, n. 2, p. 131-144, jul./dez. 2020. Disponível em: https://periodicos.unifap.br/index.php/pracs/user. Acesso em: 29 dez. 2020.

TAVARES, P. A.. Efeito do Programa Bolsa Família sobre a oferta de trabalho das mães. Economia e Sociedade, Campinas, v. 19, n. 3, p. 613-635, 2010. Disponível em: Microsoft Word - Economia e Sociedade 40 Artigo 8 (scielo.br). Acesso em: 10 dez. 2018.

XERENTE, V. B. Bolsa família na área Akwẽ-Xerente: problematizando o impacto do programa na aldeia Nrõzawi, (terra indígena Xerente). 2015. 59 f. Monografia (Graduação, Curso de Serviço Social da Universidade Federal do Tocantins). UFT, Miracema do Tocantins, TO, 2015.

Recebido em: 26.12.2019 Aceito em: 06.01.2021 